1 Fundação Oswaldo Cruz (Fiocruz), Instituto Nacional da Saúde da Mulher da Criança do Adolescentes Fernandes Figueira (IFF) - Rio de Janeiro (RJ), Brasil. katia@iff.fiocruz.br

2 Fundação Oswaldo Cruz (Fiocruz), Escola Nacional de Saúde Pública Sergio Arouca (Ensp), Departamento de Administração e Planejamento em Saúde (Daps) - Rio de Janeiro (RJ), Brasil. creuzadasilvaazevedo@ gmail.com

3 Fundação Oswaldo Cruz (Fiocruz), Escola Nacional de Saúde Pública Sergio Arouca (Ensp) - Rio de Janeiro (RJ), Brasil. simone@ensp.fiocruz.br

\section{A dinâmica do reconhecimento: estratégias dos Bombeiros Militares do Estado Rio de Janeiro}

\author{
The dynamics of acknowledgement: strategies of the Military \\ Firefighters of the State of Rio de Janeiro
}

Kátia Maria Oliveira de Souza', Creuza da Silva Azevedo² Simone Santos Oliveira ${ }^{\mathbf{3}}$

RESUMO O estudo analisa, sob a ótica da Psicodinâmica do Trabalho, a dinâmica do reconhecimento e as estratégias utilizadas pelos bombeiros militares do Rio de Janeiro ante as negociações por melhores salários e condições de trabalho. Trata-se de um estudo qualitativo, com utilização de entrevistas tratadas por meio de análise temática. Os resultados apontaram que a falta de reconhecimento pode desencadear sofrimento para o trabalhador e afetar a sua saúde. Os bombeiros militares, no diálogo com os gestores, utilizaram uma estratégia coletiva ao mobilizar a população, que, por meio do julgamento de utilidade, expressou o reconhecimento simbólico capaz de impulsionar as negociações.

PALAVRAS-CHAVE Bombeiros. Estratégias de enfrentamento. Saúde do trabalhador.

ABSTRACT The study analyzes from the perspective of work psychodynamics, the dynamics of the acknowledgement and the strategies used by firefighters in Rio de Janeiro before the negotiations for better wages and work conditions. This is a qualitative study, using interviews treated through thematic analysis. The results pointed that the lack of acknowledge can develop suffering for workers and affect their health. The military firemen, in dialogue with the managers, used a collective strategy to mobilize the population, which, through the judgment of usefulness, expressed the symbolic recognition that is able to boost negotiations.

KEYWORDS Firefighters. Adaptation psychological. Occupational health. 


\section{Introdução}

No contexto brasileiro, os bombeiros militares são trabalhadores que prestam serviços públicos de proteção contra incêndios, ações de salvamentos, resgates e ações da defesa civil em acidentes ou envolvendo produtos classificados como perigoso à vida e à saúde das pessoas (CARDOSO, 2004). Trata-se de profissionais que atuam em um conjunto diversificado de atividades, com o objetivo de salvar vidas, seja no céu, no mar ou na terra.

Apesar da potencialidade da atividade, os registros acenam que questões acerca do reconhecimento da profissão já marcaram de maneira importante um período da história, pois, na antiguidade, os bombeiros não pertenciam ao grupo dos trabalhadores formais, eram soldados e escravos selecionados pela robustez e coragem, fazendo perceber que a competência não era um critério essencial (BMRS, 2010).

Atualmente, no Brasil, a profissão é regulamentada pelas regras trabalhistas comuns aos militares, sendo o ingresso na carreira realizado por meio de concurso público, elaborado com alto nível de exigência no que se refere ao conhecimento das competências. Essa evolução favoreceu uma mudança de percepção da sociedade sob os profissionais bombeiros. O status do passado histórico de escravos cedeu lugar ao destacado nível de confiabilidade social, constituindo um imaginário heroico, consequência da competência e destreza, no campo da prestação dos serviços para os quais são preparados (SOUZA; VELLOSO; OLIVEIRA, 2012).

Tal nível de confiabilidade da sociedade, contudo, ainda que expresse uma forma de reconhecimento, não é suficiente para garantir boas condições salariais. Basta recordar que, para a categoria dos bombeiros militares do Rio de Janeiro, o ano de 2011 foi marcado por uma série de difíceis negociações pautadas em melhores condições de trabalho e salários mais justos; ainda que, nesse mesmo ano, tenham atuado de maneira decisiva com grande reconhecimento da população e da mídia em função do desempenho no evento ocorrido na Região Serrana do estado. Ocasião em que aconteceu o maior desastre relacionado com a água na história do País e o décimo pior do mundo na última década com 30 mil desabrigados e 916 vítimas fatais (PORTELLA; NUNES, 2014). Nesse evento, entre as vítimas, havia três bombeiros em atividade de salvamento. Apenas 90 dias após o evento do qual participou grande parte da corporação do estado, esses trabalhadores enfrentaram dificuldades nas negociações por melhores condições de trabalho e salário.

No caso dos bombeiros militares, tanto as motivações contidas na pauta de negociações, tais como falta de recursos materiais, baixos salários e carga de trabalho intensa, quanto a falta de reconhecimento podem interferir de forma significativa na sua qualidade de vida e de saúde. Principalmente ao se levar em consideração as especificidades da natureza do trabalho em que os profissionais atuam, sob um clima de tensão, necessitam de precisão nas tomadas de decisões, lidam com imprevistos e colocam em risco a própria vida. Apesar da exposição aos riscos, nem sempre as formas de adoecimento são explicitas, deixando parecer pouca ou nenhuma relação entre o trabalho e a saúde.

A partir da Psicodinâmica do Trabalho (PDT), a luta pelo reconhecimento pode ser entendida pela dinâmica da contribuição e retribuição, com base na cooperação e na confiança dos coletivos. Nesse sentido, para acessar as incoerências, contradições e sistemas de defesa, o referencial da psicodinâmica do trabalho desenvolvido pelo psiquiatra e psicanalista francês Christophe Dejours (2004) oferece aportes teóricos para reconhecer os fenômenos subjetivos individuais ou coletivos que revelam a face do prazer obtido pelos profissionais em suas atividades ou as formas inconscientemente utilizadas para ocultar adoecimentos e sofrimentos.

A cooperação é a expressão do desejo que 
mobiliza os sujeitos para uma ação coletiva. Portanto, é necessário emergir espontaneamente, pois surge da vontade de unir-se aos outros trabalhadores para o enfrentamento das contradições do trabalho e da organização (DEJOURS, 1997, 2004). A cooperação envolve o comprometimento entre os sujeitos, por isso pressupõe um processo de discussão para a construção das regras, deliberações que norteiam o modo de trabalhar. Para haver cooperação, é fundamental a confiança e segurança em relação aos parceiros e à organização. $\mathrm{O}$ peso da confiança mútua exige a transparência de todos os ajustes singulares necessários para atender aos imprevistos não contemplados nas prescrições formuladas pela organização. Por isso, Dejours, Abdoucheli e Jayet, (2007) reforçam que a cooperação é um compromisso técnico e social, que proporciona aos sujeitos um convívio dinâmico, e, consequentemente, os expõe às críticas geradas nos espaços coletivos.

Sob a ótica da psicodinâmica do trabalho, é possível analisar algumas particularidades importantes na profissão dos bombeiros militares e as correlações com a saúde desses profissionais. Uma delas se relaciona com a predominância masculina na profissão, sustentada por uma forte expressão da virilidade desses trabalhadores. Eles preferem, apesar de todo risco inerente à atividade, enfrentar silenciosamente os medos, dores e sofrimentos; situação reforçada pela rígida e hierárquica organização militar. Um fenômeno identificado como um recurso simbólico referente à negação do medo, do perigo que não protege e, contraditoriamente, pode camuflar a realidade relativa às formas de adoecimentos (DEJOURS, 2006). Outro exemplo se relaciona com o que a mídia produz ao alimentar a imagem heroica dos profissionais associando atributos de coragem e força, nas ocasiões de eventos extremos. Como efeito indesejado, a crença do heroísmo e da onipotência podem camuflar notificações de adoecimento e levar ao agravamento de quadros de histórias de distúrbios emocionais (FRANCO, 2010).
O objetivo deste artigo é analisar a dinâmica do reconhecimento e as estratégias utilizadas pelos bombeiros militares do Rio de Janeiro ante as negociações por melhores salários e condições de trabalho.

\section{Metodologia}

$\mathrm{O}$ artigo apresenta parte dos resultados de uma investigação desenvolvida em tese de doutorado no campo da saúde pública (souzA, 2013), cujo objetivo foi a análise da relação estabelecida entre a saúde e o trabalho, no contexto da atividade do bombeiro militar no Rio de Janeiro. A produção de dados ocorreu no segundo semestre de 2011, no mesmo ano em que os bombeiros militares do Rio Janeiro negociavam por direitos à saúde e ao trabalho. Incorpora também resultados de pesquisa realizada, em 2015, com bombeiros residentes da Região Serrana afetada pelo desastre de 2011.

Para tanto, foi utilizada a abordagem qualitativa e, portanto, compreensiva, com o propósito de considerar a experiência dos sujeitos e dimensão intersubjetiva dos trabalhadores no contexto organizacional, explorando as significações, crenças, valores e atitudes dos profissionais aos prestarem os serviços (MINAYO, 1994). Turato (2008) aponta que o cerne do método qualitativo está em torno das construções de sentidos e significações, que são capturados em circunstâncias criadas pelo pesquisador ao se dispor a ouvir e observar os sujeitos da pesquisa e realizar interpretações para compreender os fenômenos.

No caso do primeiro estudo, a pesquisa de campo teve seu início por meio do acesso e seleção às fotos dos trabalhadores atuando em diversas modalidades de socorro. Essas fotos, do acervo da corporação, foram utilizadas como um disparador das narrativas produzidas nas entrevistas. Desse modo, após o primeiro momento de observação das fotografias, os profissionais respondiam às 
perguntas elaboradas com base no roteiro da entrevista semiestruturada. A participação dos profissionais nas entrevistas contou primeiramente com o militar que recepcionou a pesquisadora, sendo os demais entrevistados uma sequência de indicações. Formou-se, assim, o efeito 'bola de neve', um procedimento sinalizado por Nicolaci (2007) capaz de produzir uma amostra heterogênea. Esse modelo de indicação resultou no total de 20 entrevistas com bombeiros de variadas patentes e idades.

No caso da segunda pesquisa, para realização das visitas às corporações, foram feitos contatos telefônicos para agendamento prévio. Nelas foram realizadas entrevistas semiestruturadas com grupos de 5 trabalhadores em cada unidade, o que representou um total de 15 profissionais. O critério para escolha desses profissionais foi o de ter trabalhado no socorro às vítimas do desastre.

Ambos os projetos foram submetidos e aprovados pelo Comitê de Ética e Pesquisa da Escola Nacional de Saúde Pública Sergio Arouca (Ensp/Fundação Oswaldo Cruz Fiocruz) (Protocolos de parecer 297/11 e 999912/15) e requisitaram a assinatura dos entrevistados do Termo de Compromisso Livre e Esclarecido (TCLE).

\section{Discussão e resultados}

\section{Contextualização da luta dos bom- beiros militares}

No período de 14 de abril até 28 de junho de 2011, a cidade do Rio de Janeiro foi o palco de intensas e inusitadas manifestações organizadas pelos bombeiros militares. Estes protestavam por melhorias salariais e condições de trabalho. No que se refere às relações de trabalho, os principais itens da pauta eram: vale transporte e aumento do piso salarial. Quanto às condições de trabalho, o pleito principal era dos salva-vidas como a necessidade proteção solar e óculos de sol, configurados como acessórios fundamentais para o exercício de suas atividades. Também constavam na lista o reforço da alimentação para os profissionais que permanecem durante longo tempo de expediente em uma escala de $12 \mathrm{~h}$ por $36 \mathrm{~h}$. Alguns equipamentos fundamentais para o bom exercício das atividades foram lembrados, como: tampões de ouvido, binóculos, nadadeira, rescue-tube (boia especial para salvamento), pocket-mask (máscaras de ventilação para o uso em afogados) viaturas, jet-skis e quadriciclos.

O momento auge das reivindicações ocorreu no dia 4 junho de 2011, quando o Quartel do Comando Central da Corporação foi ocupado por 2 mil manifestantes. A dificuldade de diálogo com os gestores foi a principal justificativa para a ocupação. Como resposta à resistência ao diálogo, os bombeiros não atenderam à ordem de retirada do Quartel Central. O governador do Rio de Janeiro solicitou ao Batalhão de Operações Especiais (Bope) providências quanto à desocupação imediata.

Em consequência, instalou-se um clima geral de tensão e conflito, expressos na depredação do patrimônio do quartel e prisão de 439 bombeiros militares participantes do movimento. $\mathrm{O}$ fato teve grande repercussão nas redes sociais, levando a uma rápida disseminação do movimento recebendo apoio de outras corporações de todo o País.

No desenrolar desses fatos, em 12 de junho, na orla de Copacabana, foi organizada a manifestação nomeada 'Rio Vermelho' em apoio à anistia criminal e administrativa dos bombeiros detidos. No evento, estiveram presentes cerca de 20 mil pessoas. A manifestação foi organizada com a participação da população e de outras categorias como a dos policiais militares. Algumas estratégias foram utilizadas para marcar visivelmente a adesão da população. Uma faixa levada por um avião fretado sobrevoou a orla de Copacabana 
para chamar a atenção da sociedade fluminense. Constava na faixa: 'Bombeiros pedem socorro. População carioca, precisamos de vocês'. Todos os participantes trajaram roupas vermelhas, e foram expostos panos da mesma cor nas janelas. Outra estratégia foi a fixação de adesivos nos veículos e fitas vermelhas nas antenas de motos e carros.

Sobre esse movimento, a questão do reconhecimento da atividade exercida pelos bombeiros militares apresentou-se de forma recorrente no discurso dos entrevistados, apontando um peso importante nos resultados obtidos no estudo.

\section{Dinâmica do reconhecimento e a re- lação saúde-trabalho}

Segundo Dejours e Gernet (2011), o olhar do outro em forma de reconhecimento, da contribuição social e técnica para a organização do trabalho imprime importante registro na identidade do trabalhador. A contribuição se dá por meio da mobilização do trabalhador no processo de trabalho, no confrontado com imposições e limitações das normas e da hierarquia. Portanto, o reconhecimento também pode ser simbólico, no sentido de gratidão pela contribuição dos trabalhadores à organização, estabelecendo uma dinâmica pautada na contribuição versus retribuição (DEJOURS, 2004).

No quer se refere ao julgamento, Dejours (2004) expõe duas formas distintas: julgamento da utilidade e julgamento estético, ambos construídos rigorosamente acerca do trabalho concluído pelos autores engajados na gestão de sua organização. O primeiro julgamento é formulado pelos superiores hierárquicos que avaliam a qualidade do trabalho efetuado numa relação vertical. Já o segundo julgamento - estético ou de beleza - é visto como muito exigente e severo, por ser proferido pelos pares. Este último oferece ao sujeito uma troca entre a sua contribuição e o reconhecimento dos pares: o sujeito é reconhecido como possuindo todas as qualidades daqueles que formam o coletivo de trabalho, ou seja, a equipe ou a comunidade à qual pertence. (DEJOURS, 2004, P. 187).

Fatores como originalidade, criatividade e inovação são pertinentes ao conceito de beleza; portanto, é preciso visibilidade para fazer o sujeito ser reconhecido.

Dejours (2004), assim, é categórico ao afirmar que a psicodinâmica do trabalho defende a hipótese de que o trabalho não é redutível a uma atividade de produção no mundo objetivo, posto que sempre coloca à prova a subjetividade. Isso significa que os impasses, os truques, os entraves, a inteligência e todas as artimanhas utilizadas para que a atividade seja executada fazem parte do trabalho, principalmente pelo fato desses aspectos pertencerem a um campo de pouca ou nenhuma visibilidade.

Como forma de fortalecimento, o bombeiro militar buscou o apoio da população, mobilizando os usuários e despertando a atenção das autoridades públicas. A inclusão da população traz para a cena o julgamento de utilidade que é de natureza social e pode ser proferido também pelos clientes ou público-alvo; sendo uma estratégia do processo para obtenção do reconhecimento (DEJOURS, 2004).

[...] ninguém gosta de trabalhar desmotivado... em termos financeiros... nós seres humanos temos a necessidade de ter o reconhecimento... o reconhecimento dos nossos filhos... nossa esposa e vice-versa... e nós queremos o reconhecimento. (E3).

De forma mais ampla, o mérito de reconhecimento parece ocupar lugar de pouca relevância nas discussões relativas à gestão nessa corporação. Sem o reconhecimento do Estado, os bombeiros militares utilizaram uma estratégia para levar ao conhecimento do seu público-alvo as necessidades da classe. Para tanto, deram visibilidade às situações de descontentamento. Na concepção de Clot (2006), expuseram à população o 
real da sua atividade ao evidenciar de forma pública as carências relativas às condições de trabalho e as dificuldades de negociação com seus gestores, pois, segundo esse autor, a atividade não é somente o que se faz, mas também o que deixou de ser feito por impedimentos (ou descontentamentos).

Embora a lógica de coletivo de trabalho refira-se ao campo interno da organização, no caso dos bombeiros militares, a estratégia de dar visibilidade ao real da atividade proporcionou um tipo de extensão desse coletivo, pelo menos no que diz respeito ao apoio nas negociações. De acordo com Dejours (2012), nas atividades de risco à integridade física, a dimensão do risco intensifica o medo e catalisa a formação de tipos de coletivos que não são fundados sobre a mesma referência.

O conceito de atividade em sua complexidade abarca muitos aspectos, inclusive, a dimensão coletiva. Para Brito (2008), as instâncias do coletivo oferecem condições favoráveis à mobilização subjetiva, por estar sustentado na base da confiança que promove a cooperação espontânea. Também é no campo coletivo que se torna possível a visibilidade da inteligência mobilizada pelo trabalhador e seu saber-fazer, possibilitando, graças ao rompimento da invisibilidade do trabalho, alguma forma de reconhecimento (DEJOURS, 2004). A participação da população foi um importante indicativo de reconhecimento para os bombeiros.

No movimento dos bombeiros, quando pedimos socorro para a população, fomos bem aceitos nesse pedido de socorro porque conseguimos colocar mais de 20 mil pessoas na orla de Copacabana, e outros milhares de pessoas com fitas nos carros. Achei que isso aí foi uma resposta que, sem sombra de dúvidas, é uma profissão que é bem aceita pela população. (E2).

Sendo a confiança um componente importante na dinâmica do reconhecimento, vale um destaque para os resultados obtidos por meio de um comparativo de índice de confiança social nos anos de 2009, 2010 e 2011 (iBope inteligente, 2012). O Corpo de Bombeiros ocupou o segundo lugar com pontuação de 86,85 e 86 , quando a pontuação máxima era 100. Esse resultado pode explicar a adesão da população ao movimento reivindicatório. Pode-se inferir que a confiança social também está vinculada ao julgamento por estética. Nesse sentido, aponta-se a adesão de outras categorias da segurança pública, como a polícia militar e a guarda municipal, que apoiaram e aprovaram o 'modo operatório' da categoria dos bombeiros militares. Um dos fatores mais importantes desse julgamento é a especificidade da atividade, o que significa dizer que nenhum outro profissional é capaz de fazer o que profissional da área específica faz, mesmo que siga as prescrições e normas básicas de procedimento. A confiança exerce um peso decisivo para que a cooperação seja estabelecida dentro da dinâmica do reconhecimento. Para o trabalhador, ela promove o desenvolvimento da atividade, da segurança e da saúde mental (RUIZ; ARAúso, 2012; CASTRO; MERLO, 2011).

A falta de reconhecimento é um fator impactante em relação à subjetividade e à saúde do trabalhador; caso a dinâmica do reconhecimento esteja paralisada, torna-se indisponível o espaço para transformar o sofrimento em prazer. Equivale dizer que o sofrimento exerce uma pressão maior na dinâmica, impossibilitando qualquer tipo de alternância ao seu par: o prazer (DEJOURS, 2004). Por isso, pode-se dizer que o homem sempre será afetado por seu trabalho, em uma dinâmica na qual sua atividade pode ser fonte de prazer ou de sofrimento.

O trabalhador tende a se mobilizar para adquirir reconhecimento e, assim, transformar o sofrimento em prazer, na busca de uma forma saudável e, muitas vezes, criativa de retomar ou reinventar o sentido do trabalho. Caso seja impossível a mobilização para a obtenção de reconhecimento e, consequentemente, do prazer, o trabalho perde 
o sentido. Assim, o sofrimento equivale ao acúmulo de uma pressão que promove o desequilíbrio da dinâmica, podendo gerar uma descompensação psíquica ou somática (DEJOURS, 2004).

Dejours pontua que o reconhecimento pelo outro é indispensável para a validação de uma descoberta exitosa na sua confrontação do real e confirmação de sua identidade: "O sujeito sem o reconhecimento é levado a duvidar da relação que ele mantém com o real, a duvidar dele mesmo, [...]" (DEJOURS; GERNET, 2011, P. 64). Diante desta afirmativa, o autor atribui ao reconhecimento um caráter de participação na construção da identidade dos sujeitos. Isso porque, quando se tem uma constatação positiva sobre o saber-fazer, pode-se agregar esse registro à identidade. Essa é a razão pela qual o trabalho extrapola a lógica de produzir bens e serviços para a transformação de si mesmo (DEJOURS, 2011). O avesso dessa relação coloca em risco a identidade do sujeito, posto que, não havendo a retribuição por meio do reconhecimento, o trabalhador passa a desconsiderar todo o seu investimento, inclusive o subjetivo.

Em decorrência do trabalho no campo das emergências, pode-se dizer que os bombeiros militares são vulneráveis às situações que produzem alto nível de estresse (LIMA; ASSUNÇÃO; BARRETO, 2015). Nas situações de desastres como o ocorrido na Região Serrana em 2011, os bombeiros se mantiveram em longas jornadas, realizando trabalho de resgate, recolhimento e busca de corpos nos quais incluíram seus pares de atividade e familiares.

O mais impactante não foi o fator de ver os cadáveres e as pessoas, porque mal ou bem é o nosso trabalho, não adiante. O pior é o fato que poderia ter acontecido com meu pai, minha mãe, minha sogra, minha cunhada, todo mundo mora ali.. perdemos dois bombeiros amigos, poderia ter sido qualquer um. (E12).

Eu realmente me emociono quando falo desta situação. Para o bombeiro que viveu esse dia por completo, não haverá nada que impressione tanto... pode ter certeza absoluta. O que a população viu por fotos, não é nada comparado ao que vimos. Passamos praticamente 10 dias sem dormir. (BM 10).

Passados quatro anos, os profissionais, ao serem entrevistados, revelaram que essa experiência foi uma das mais difíceis vivenciadas.

Tenho amigos que não são mais o que eram antes. Tenho amigos que sofreram mais até [...] porque tiveram perdas na própria família sendo bombeiros e tendo que lidar com a perda dos outros e a perda deles... tendo que trabalhar. Difícil gerenciar isso tudo. (E5).

A vivência de situações extremas pode afetar a saúde e o rendimento laboral do trabalhador, com problemas de concentração, alterações do estado de ânimo, retraimento social, abuso de substâncias psicoativas, e os problemas familiares são recorrentes (MONTEIRO ET AL., 2007). Também são observados sintomas de ansiedade, depressão e episódios de ideação suicida. Alguns estímulos podem ser dispositivos para a ocorrência de episódios agudos de medo, pânico ou agressividade, em função da recordação e/ou revivescência súbita do trauma. Por vezes, as recordações são emanadas por meio de imagens, pensamentos.

Então temos que seguir em frente e sofrer depois, porque foi algo realmente assim inacreditável né! Muita gente. Eu nunca tinha visto corpo em árvore, nunca tinha visto caminhão em cima de telhado de casas, então assim, tudo foi muito chocante. (E7).

Para Lima, Assunção e Barreto (2015), as atividades desempenhadas pelos bombeiros e a exposição aos eventos traumáticos já são suficientes para influenciar negativamente a saúde mental, independentemente de outros estressores ocupacionais; o que justifica 
relatos por alguns bombeiros da pesquisa que citaram ter adquirido alguns sintomas como insônia, ansiedade, após atuação no evento. $\mathrm{O}$ agravante é o fato que a exposição prolongada às situações estressantes leva a um efeito acumulativo que pode promover o adoecimento ao longo da carreira, influenciando diretamente a saúde física e psíquica dos profissionais (FRANCO, 2010).

Um camarada [bombeiro] estava no mar e tinha duas pessoas se afogando... ele salvou uma e quando foi salvar a outra ela afundou... ele estava pertinho... ele ficou o dia inteiro lá até a noite procurando a pessoa... não quis voltar para o quartel... não quis almoçar... não quis fazer nada. Ficou chorando... não quis parar de chorar... e dizia: eu tenho que salvar esta pessoa... eu vi, eu vi, eu vi!!! Surtou. Naquele caso você via que era um caso real, em que a pessoa estava desesperada... ela viu a pessoa [vítima] afundando olhando para a cara dela... afundou... e ela não conseguiu pegar. Ele se sentiu culpado por ter ceifado a vida de uma família que vai ... chorar... que vai ficar traumatizada o resto da vida. (E1).

A cada chamado, o profissional é apresentado a situações novas que demandam gerenciamento e decisões rápidas, das quais não se pode prever o desfecho. A narrativa em destaque indica uma situação em que o desfecho correspondeu ao limite da ordem do insuportável para o sujeito, nítida expressão de sofrimento. A cena possibilita pensar nas situações extremas, nas quais os profissionais estão sujeitos a expressar os sintomas emocionais diretamente ligados ao exercício da profissão.

Quando se fala sobre as implicações da saúde mental, como forma de expressão da noção de sofrimento no trabalho, abre-se a possibilidade de visualização da dinâmica entre reconhecimento, trabalho e saúde, uma vez que se pode inferir a possibilidade da instalação da doença de forma mais contundente em que o reconhecimento é escasso.

A falta do reconhecimento impede que o profissional interprete como legítimas as suas percepções acerca das condições de trabalho ou mesmo sobre sua vocação profissional. Dessa forma, correndo o risco de manter-se aprisionado em um cárcere, em que as algemas imobilizam a criatividade e, consequentemente, a saúde.

\section{Considerações finais}

Ao se apresentar o cenário de negociações e a atividade dos bombeiros, com sua constante mobilização subjetiva, pode-se entender que a presença de grandes tensões abalou o nível de confiança entre os gestores e trabalhadores. No contexto institucional antes da luta pública, os profissionais mantinham uma expectativa de obterem retribuição pela cooperação e solidariedade presentes no contexto do trabalho.

A falta de avanços nas negociações produziu efeitos na esfera da confiança abalada. Para se protegerem, os trabalhadores bombeiros elaboraram uma estratégica coletiva, visando restaurar as forças da classe profissional. A população e outros grupos foram convocados para fazer parte desse coletivo e, assim, formar novas relações de cooperação e solidariedade. Essa engenhosidade do coletivo contribuiu para que vencessem os obstáculos e para que as reivindicações fossem atendidas.

Destaca-se que o espaço coletivo de discussão foi o território da transformação, no qual o sofrimento deu lugar ao prazer e à obtenção do reconhecimento. Foi no coletivo que os trabalhadores exercitaram a emancipação que os levaram a pensar, politicamente, sobre o seu direto ao trabalho e à saúde. Com os novos 'aliados', foram retomados o sentido e o valor da atividade. A reboque, nessa complexa dinâmica, o reconhecimento dos gestores - via concessão dos acordos salariais - foi reconquistado, trazendo de volta o equilíbrio nas relações entre os trabalhadores e a organização.

No entanto, pode-se verificar, no caso do desastre da Região Serrana, que há ainda 
um grande caminho a ser percorrido para o reconhecimento da relação saúde-trabalho nessa atividade, principalmente nas vivências dos eventos extremos. Dar visibilidade ao sofrimento atomizado e não partilhado na corporação como uma questão coletiva que necessita de novos destinos.

\section{Agradecimentos}

Coordenação de Aperfeiçoamento de Pessoal de Nível Superior (Capes).

\section{Referências}

BRIGADA MILITAR. História. Rio Grande do Sul, 2010. Disponível em: <http://www.brigadamilitar. rs.gov.br/bombeiros/hist-mun.html>. Acesso em: 18 nov. 2010

BRITO, J. C. O trabalho real. In: PEREIRA, I. B.; LIMA, J. C. F. (Org.). Dicionário da educação profissional em saúde. 2. ed. rev. ampl. Rio de Janeiro: EPSJV. p. 440$445,2008$.

CARDOSO, A. Influências dos fatores Organizacionais no Estresse de Profissionais Bombeiros. 2004. 114 f. Dissertação (Mestrado em Psicologia) - Universidade Federal de Santa Catarina, Florianópolis, 2004.

CASTRO, T. C. M.; MERLO, A. R. C. Reconhecimento e saúde mental na atividade de segurança pública. PSICO, Porto Alegre, v. 42, n. 4, p. 474-480, out./dez. 2011.

CLOT, Y. A função psicológica do trabalho. São Paulo: Vozes, 2006.

DEJOURS, C. A banalização da Injustiça Social. Trad. Luiz Alberto Monjardim. 7. edição. Rio de Janeiro: FGV, 2006.

Fator Humano. Rio de janeiro: FGV, 1997.

Da Psicopatologia à Psicodinâmica do trabalho.

Rio de Janeiro: Fiocruz, 2004.

Subjetividade, trabalho e ação: uma visão de conjunto. In: DEJOURS, C. Trabalho vivo: trabalho e emancipação. Brasília, DF: Paralelo 15, p. 23-44, 2012.

DEJOURS, C.; ABDOUCHELI, E.; JAYET, C.

Psicodinâmica do trabalho: contribuições da Escola Dejouriana à análise da relação prazer, sofrimento e trabalho. São Paulo: Atlas, 2007.

DEJOURS, C.; GERNET, I. Avaliação do trabalho e reconhecimento. In: BENDASSOLLI, P. F.; SOBOLL, L. A. (Org.). Clínicas do trabalho novas perspectivas para compreensão do trabalho na atualidade. São Paulo: Atlas, p. 61-65, 2011.

FRANCO. M. H. P. Mentes abaladas: Exposição Diária a desastres amplia sentimentos de estresse e angústia, adoecendo os profissionais de emergência. Revista Emergência, Rio Grande do Sul, n. 23, p. 24-32, 2010. Disponível em: <http://docsll.minhateca.com. br/442004082,BR,0,0,Revista-Emerg\%C3\%AAncia-Ed23_Especial---Apoio-psicol\%C3\%B3gico-aobombeiro.pdf $>$. Acesso em: 10 jan. 2011.

IBOPE INTELIGÊNCIA. Índice de Confiança Social. 2012. Disponível em: <http://www4.ibope.com.br/download/relatorio_ics_set.pdf $>$. Acesso em: 20 ago. 2012.

LIMA, E. P.; ASSUNÇÃO, A. A.; BARRETO, S. M.

Transtorno de Estresse Pós-Traumático (TEPT) em 
Bombeiros de Belo Horizonte, Brasil: Prevalência e Fatores Ocupacionais Associados. Psicologia: Teoria e Pesquisa. Brasília, DF, v. 31 n. 2, p. 279-288, jun. 2015.

MINAYO, M. C. S. O desafio do conhecimento: pesquisa qualitativa em saúde. São Paulo: Hucitec, 1994.

MONTEIRO, J. K. et al. Bombeiros: um olhar sobre a qualidade de vida no trabalho. Psicologia: Ciência e Profissão. Brasília, DF, v. 27, n. 3, p. 554-565, set. 2007.

NICOLACI, A. M. C. O campo da pesquisa qualitativa e o Método de Explicitação do Discurso Subjacente (MEDS). Psicologia: Reflexão e Crítica. Porto Alegre: v. 20, n. 1, p. 65-73. 2007.

PORTELLA, S. L. D.; NUNES, J. A. Populações serranas excluídas, cidades insustentáveis: o enigma da participação pública. Ciência \&t Saúde Coletiva, Rio de Janeiro, v. 19, n. 10, p. 4223-4228, out. 2014.

RUIZ, S. V.; ARAÚJO, A. L. L. Saúde e segurança e a subjetividade no trabalho: os riscos psicossociais. Revista Brasileira Saúde Ocupacional, São Paulo, v. 37, n. 125, p. 170-180, 2012.
SOUZA, K. M. O. A análise da relação trabalho e saúde na atividade dos bombeiros militares do Rio de Janeiro. 154 f. Tese (Doutorado em Saúde Pública) - Escola Nacional de Saúde Pública Sergio Arouca, Fundação Oswaldo Cruz, Rio de Janeiro, 2013.

SOUZA, K. M. O.; VELLOSO, M. P.; OLIVEIRA, S. S. A profissão de bombeiro militar e a análise da atividade para compreensão da relação trabalho - saúde: revisão da literatura. In: LOURENÇO, E. A. S.; NAVARRO, V. L.; LARA, R.; INÁCIO, J. R. (Org.). Saúde do trabalhador: desafios para a seguridade social e movimento sindical. São Paulo: Cultura Acadêmica; Unesp, p. 257-268. 2012.

TURATO, E. R. Tratado da metodologia clínico-qualitativa: construção teórico-epistemológica, discussão comparada e aplicação nas áreas da saúde e humanas. 3. ed. Petrópolis, RJ: Vozes, 2008.

Recebido para publicação em agosto de 2016

Versão final em dezembro de 2016

Conflito de interesses: inexistente

Suporte financeiro: não houve 